\title{
UJI DAYA HAMBAT PERASAN BUAH BELIMBING WULUH (Averrhoa bilimbi L) TERHADAP PERTUMBUHAN Propionibacterium acnes
}

\author{
Rusdiaman*) \\ *) Jurusan Farmasi Poltekkes Kemenkes Makassar
}

\begin{abstract}
ABSTRAK
Penelitian ini adalah penelitian eksperimental laboratorium bertujuan untuk menentukan besarnya daya hambat perasan Buah Belimbing Wuluh (Averrhoa bilimbi L.) terhadap pertumbuhan Propionibacterium acnes. Bahan uji yang digunakan pada penelitian ini adalah Buah Belimbing Wuluh (Averrhoa bilimbi L.) yang mengandung senyawa antibakteri yaitu Flavonoid, Saponin, dan Tanin. Buah Belimbing Wuluh (Averrhoa bilimbi L.) yang berasal dari Kota Makassar, Sulawesi Selatan kemudian dibuat perasan dengan konsentrasi 50\% v/v, 75\% v/v, 100\% v/v, kontrol negatif (Aqua Destilata Steril), dan kontrol positif (Klindamisin). Pengujian dilakukan dengan metode difusi agar. Hasil pengujian diperoleh diameter zona hambatan rata-rata untuk konsentrasi $50 \%$ yaitu $18,67 \mathrm{~mm}$, untuk konsentrasi $75 \%$ yaitu $18,67 \mathrm{~mm}$, untuk konsentrasi $100 \%$ yaitu $21 \mathrm{~mm}$, sedangkan pada kontrol positif yaitu 23,3 mm dan kontrol negatif tidak ditemukan adanya zona hambat.
\end{abstract}

\section{Kata kunci : Buah Belimbing Wuluh, Perasan, Uji Daya Hambat, Propionibacterium acnes}

\section{PENDAHULUAN}

Kulit menjadi bagian yang paling besar bagi tubuh manusia. Kulit menutupi semua bagian organ tubuh, sehingga penampilan menjadi lebih menarik. Hal itulah ketika ada beberapa bagian kulit yang terserang penyakit, maka bisa menyebabkan seseorang menjadi tidak percaya diri. Adapun selain dari produksi kelenjar minyak yang berlebihan faktor yang menjadi penyebab munculnya jerawat adalah bakteri. Bakteri yang menyebabkan timbulnya jerawat dikulit salah satunya adalah Propionibacterium acnes.

Propionibacterium acnes bersifat aerotoleran (tumbuh secara anaerob dan aerob). Propionibacterium acnes termasuk bakteri yang tumbuh relatif lambat. Karakteristik dari bakteri Propionibacterium acnes yang terlihat pada pewarnaan gram positif adalah sangat pleomorfik, berbentuk batang atau panjang dengan ujung yang melengkung, berbentuk gada, dengan pewarnaan yang tidak rata dan bermanikmanik, dan kadang-kadang berbentuk kokoid atau bulat. Bakteri ini dapat tumbuh di udara dan tidak menghasilkan endospora. Propionibacterium acnes memerlukan oksigen mulai dari aerob atau anaerob fakultatif sampai ke mikroerofilik atau anaerob. Beberapa bersifat patogen untuk hewan dan tanaman. (Sari, A., R., 2015).
Propionibacterium acnes ikut serta dalam patogenesis jerawat dengan menghasilkan lipase, yang memecahkan asam lemak bebas dari lipid kulit. Asam lemak ini dapat menimbulkan radang jaringan dan ikut menyebabkan jerawat (Brooks et al.,2007).

Propionibacterium acnes adalah flora normal kulit terutama di wajah yang tergolong dalam kelompok bakteri Corynebacteri. Bakteri ini berperan pada patogenesis jerawat yang dapat menyebabkan inflamasi. Pengobatan yang dapat diakukan untuk mengatasi jerawat salah satunya dengan menggunakan bahan yang berasal dari alam yang sering kita jumpai yaitu Buah Belimbing Wuluh (Averrhoa bilimbi L.).

Menurut peneliti sebelumnya Pratiwi Raehanun (2015) mengenai Uji Daya Hambat Perasan Jeruk Nipis (Citrus aurantifolia) teradap Propionibacterium acnes dan hasilnya menyatakan bahwa Perasan Jeruk Nipis (Citrus aurantifolia) dapat menghambat pertumbuhan Propionibacterium acnes dimana diketahui Buah Jeruk Nipis mengandung Vitamin C yang juga terdapat dalam kandungan Buah Belimbing Wuluh, sehingga peneliti tertarik untuk melakukan penelitian tentang daya hambat Perasan Buah Belimbing Wuluh (Averrhoa bilimbi L.) terhadap Propionibacterium acnes. 
Berdasarkan latar belakang di atas maka ditarik rumusan masalah yaitu Apakah Perasan buah belimbing wuluh (Averrhoa bilimbi L.) dapat menghambat pertumbuhan Propionibacterium acnes?

\section{Tujuan Penelitian}

Penelitian dilakukan bertujuan untuk menentukan besarnya daya hambat Perasan Buah Belimbing Wuluh (Averrhoa bilimbi L.) terhadap pertumbuhan Propionibacterium acnes.

\section{Manfaat Penelitian}

1. Menambah pengetahuan masyarakat tentang manfaat obat tradisional dari perasan Buah Belimbing Wuluh (Averrhoa bilimbi $\quad$ L.) terhadap Propionibacterium acnes.

2. Menambah data ilmiah tentang pengobatan tradisional untuk mencegah dan mengobati penyakit infeksi yang disebabkan oleh bakteri Propionibacterium acnes.

\section{METODE DAN BAHAN}

\section{Jenis Penelitian}

Penelitian ini merupakan penelitian eksperimental laboratorium untuk menentukan besarnya daya hambat perasan buah belimbing wuluh (Averrhoa bilimbi L) terhadap pertumbuhan Propionibacterium acnes.

\section{Waktu Dan Tempat Penelitian}

Penelitian dilakukan pada bulan April 2017 di Laboratorium Mikrobiologi Jurusan Farmasi Politeknik Kemenkes Makassar.

\section{Tempat Pengambilan Bahan Uji}

Bahan uji diperoleh dari Pohon Belimbing di Makassar Sulawesi Selatan.

\section{Alat Dan Bahan Yang Digunakan}

1. Alat Yang Dugunakan :

Autoklaf, batang pengaduk, gelas ukur, labu erlenmmeyer $250 \mathrm{ml}$, aluminium foil, pinset, bunsen, corong, timbangan analitik, kain flanel, spoit, cawan petri, rak tabung, jangka sorong, panel, kapas, laminar air flow, masker, ose, oven, paper disk, tabung reaksi,water bath dan alat pelarut.
2. Bahan Yang Digunakan

Air suling, Kertas pH, Nutrien Agar (NA), MHA, Bahan uji Buah Belimbing Wuluh dan sampel Propionibacterium acnes.

\section{Prosedur Penelitian}

1. Penyiapan Bahan

a. Pengambilan dan Pengolahan Bahan Uji

Bahan uji berupa Buah

Belimbing Wuluh (Averrhoa bilimbi L.) yang telah masak dipetik lalu buah belimbing dicuci bersih lalu ditimbang sebanyak 50 gram, lalu Buah Belimbing dihaluskan menggunakan juser lalu bahan uji selanjutnya disaring lalu bahan uji yang telah disaring kemudian dikumpulkan dan disterilkan. Kemudian didinginkan dan dibuat ke dalam 3 konsentrasi yang berbeda yaitu $50 \%, 75 \%$, $100 \%$, dengan cara bahan uji Perasan Buah Belimbing Wuluh diukur menggunakan spoit sesuai dengan konsentrasi yang ingin dibuat lalu ditambahkan dengan Aqua Destilata Steril.

b. Pembuatan Media NA

Guna membuat $100 \mathrm{ml}$ media NA di timbang 2,0 gram media NA lalu dimasukkan ke dalam erlenmeyer, dilarutkan dengan 100 ml Aqua Destilata lalu Dicek pH $7,0 \pm 0,2$ lalu setelah itu dipanaskan sampai mendidih dan larut sempurna kemudian setelah larut sempurna disumbat kapas lalu disterilkan dalam autoklaf selama 15 menit pada suhu $121^{\circ} \mathrm{C}$ dengan tekanan 1-1,5 atm.

c. Pembuatan Suspensi Klindamisin $30 \mathrm{ppm}$

Ditimbang setara dengan 50 mg Klindamisin, kemudian dimasukkan kedalam lumpang lalu ditambahkan larutan koloidal Na.CMC $1 \%$ b/v sambil digerus hingga volume $100 \mathrm{ml}(500 \mathrm{ppm}$, Stok 1) selanjutnya dipipet $6 \mathrm{ml}$ (Stok 1) ditambahkan hingga volume $100 \mathrm{ml}$ (30 ppm). 
2. Penyiapan Sampel Bakteri

a. Peremajaan Kultur

Propionibacterium acnes $\mathrm{Uji}$

Propionibacterium acnes

diambil 1 ose Kemudian diinokulasikan dengan cara digoreskan pada medium NA secara miring dan dilakukan pada suhu $37^{\circ} \mathrm{C}$ selama 24 jam sehingga diperoleh biakan murni

Propionibacterium acnes.

b. Pembuatan Suspensi

Hasil biakan murni yang diperoleh disuspensikan dengan Aqua Destilata Steril dengan standard mcfarland $0,5 \quad\left(1 \times 10^{8}\right.$ CFU/ml).

\section{Pengujian Daya Hambat}

Disiapkan medium MHA steril, didinginkan hingga suhu sekitar $45^{\circ} \mathrm{C}$ kemudian dituang secara aseptis ke dalam cawan petri steril sebanyak $20 \mathrm{ml}$. Dan dibiarkan memadat kemudian digoreskan suspensi bakteri menggunakan swab steril pada media yang telah padat tadi lalu 5 buah paper disk direndam didalam konsentrasi Perasan Belimbing Wuluh yang berbeda. Paper disk 1-3 masing-masing diisi dengan Perasan Belimbing Wuluh yang telah dibuat dengan konsentrasi 50\%, 75\%, $100 \%$, paper disk ke-4 diisi dengan kontrol negatif (air suling), sedangkan paper disk ke-5 diisi dengan kontrol positif (Klindamisin) lalu paper disk diletakkan secara aseptis di atas permukaan media yang telah padat dengan jarak lebih kurang sama dengan yang lainnya lalu selanjutnya diinkubasi pada suhu $37^{\circ} \mathrm{C}$ selama $1 \times 24$ jam.

\section{Pengamatan dan Pengukuran Diameter Hambatan}

Pengamatan dan pengukuran diameter hambatan dilakukan dengan menggunakan jangka sorong setelah diinkubasikan selama $1 \times 24$ jam dan dicatat pada tabel pengamatan.

\section{HASIL DAN PEMBAHASAN}

Hasil Penelitian

Tabel 1 Hasil pengukuran Daya Hambat Perasan Buah Belimbing Wuluh (Averrhoa bilimbi L.). Pengukuran dilakukan menggunakan mistar dalam milimeter.

\begin{tabular}{llllll}
\hline \multirow{2}{*}{ Replikasi } & \multicolumn{5}{l}{ Kelompok Perlakuan/Diameter Zona Hambatan (mm) } \\
\cline { 2 - 6 } & Kontrol & Kontrol & Perasan Buah Belimbing Wuluh \\
\cline { 3 - 6 } & Negatif & Positif & $50 \%$ & $75 \%$ & $100 \%$ \\
\hline I & 0 & 24 & 20 & 20 & 22 \\
II & 0 & 22 & 18 & 18 & 20 \\
III & 0 & 24 & 18 & 18 & 21 \\
\hline Total & 0 & 70 & 56 & 56 & 63 \\
\hline Rata-rata & 0 & 23,3 & 18,67 & 18,67 & 21
\end{tabular}

Sumber Data : Data primer 2017

\section{Pembahasan}

Penelitian yang telah dilakukan di Laboratorium Biologi Farmasi Politeknik Kesehatan Kemenkes Makassar ini bertujuan untuk menentukan besarnya daya hambat Perasaan Buah Belimbing Wuluh (Averrhoa bilimbi) terhadap pertumbuhan Propionibacterium acnes, dengan melihat zona hambatan pada setiap konsentrasi. Pada penelitian ini digunakan bahan uji Buah Belimbing Wuluh (Averrhooa bilimbi L.).

Metode Ekstraksi yang digunakan untuk mengekstraksi atau menarik zat aktif dari sampel Buah Belimbing Wuluh (Averrhooa bilimbi L.) yaitu metode perasan dengan mengunakan alat yaitu juicer, karena bahan uji yang digunakan memiliki kandungan senyawa yang tidak tahan dengan pemanasan selain itu metode ini tidak membutuhkan waktu yang lama, sehingga metode ini dapat digunakan oleh masyarakat.

Buah Belimbing Wuluh (Averrhooa bilimbi L.) mengandung zat aktif yang berperan sebagai antibakteri diantaranya Flavonoid, Saponin, dan Tanin. Mekanisme kerja senyawa flavonoid dalam merusak sel bakteri memanfaatkan perbedaan kepolaran antara lipid penyusun sel bakteri dengan gugus alkohol pada senyawa flavonoid. 
Senyawa saponin apabila berinteraksi dengan bakteri maka dinding tersebut akan pecah atau lisis. Maka saat tegangan permukaan terganggu, zat anti bakteri akan dapat dengan mudah masuk kedalam sel dan akan mengganggu metabolisme hingga akhirnya terjadilah kematian bakteri. Sedangkan mekanisme penghambatan tannin yaitu dengan cara dinding bakteri yang telah lisis akibat senyawa saponin dan flavonoid, sehingga menyebabkan senyawa tannin dapat dengan mudah masuk kedalam sel bakteri (Laianto, S., dkk, 2014).

Klindamisin yang digunakan sebagai kontrol positif pada penelitian ini digunakan karena Klindamisin menghambat sebagian besar kokus Gram-positif dan sebagian besar bakteri anaerob salah satunya adalah Propionibacterium acnes, tetapi tidak bisa menghambat bakteri Gram-negatif aerob seperti Haemophillus, Mycplasma, dan Chlamydia.

Pengujian dilakukan dengan menggunakan 3 cawan petri dimana pada setiap cawan petri diletakkan 5 paper disk masing-masing dengan konsentrasi yang berbeda yaitu $50 \% \mathrm{~b} / \mathrm{v}, 75 \% \mathrm{~b} / \mathrm{v}, 100 \% \mathrm{~b} / \mathrm{v}$, dengan menggunakan Klindamisin sebagai kontrol positif dan Aqua Destilata Steril sebagai kontrol negatif. Pengukuran ini dilakukan secara inkubasi selama kurang lebih 24 jam didalam inkubator pada suhu $37^{\circ} \mathrm{C}$. Setelah masa inkubasi, kemudian dilakukan pengukuran dengan menggunakan jangka sorong. Zona hambatan ditandai dengan adanya lingkaran yang berwarna bening pada sekitar paper disk.

Hasil penelitian membuktikan bahwa Perasan Buah Belimbing Wuluh dapat menghambat pertumbuhan Propionibacterium acnes. Rata-rata diameter zona hambat pada konsentrasi $50 \%$ v/v yaitu $18,67 \mathrm{~mm}$, konsentrasi $75 \%$ v/v yaitu 18,67 $\mathrm{mm}$, konsentrasi $100 \%$ v/v yaitu $21 \mathrm{~mm}$, sedangkan diameter pada pembanding yang paling besar ialah kontrol positif yaitu 23,3 $\mathrm{mm}$ dan kontrol negatif yaitu $0 \mathrm{~mm}$ atau sama sekali tidak terdapat zona hambatan.

Berdasarkan hasil pengujian homogenitas diperoleh hasil homogen $(p>0,05)$ dan hasil pengujian normalitas $(\mathrm{p}<0,05)$ yang berarti distribusi data tidak normal, maka dilakukan perhitungan uji non parametic yaitu pengujian Kruskal-Wallis. Hasil perhitungan Kruskal-Wallis test untuk membedakan diantara group variabel hasilnya $0,013(\mathrm{p}<0,05)$ yang berarti ada perbedaan daya hambat pada kelompok perlakuan. untuk menentukan perbedaan daya hambat antar perlakuan dilanjutkan dengan Mann-Whitney Test. Hasil yang diperoleh menunjukkan bahwa konsentrasi $50 \%, 75 \%, 100 \%$ memiliki aktivitas yang sama sehingga konsentrasi yang memiliki aktivitas yang optimal adalah konsentrasi $50 \%$ yang telah dapat menghambat pertumbuhan Propionibacterium acne

\section{PENUTUP}

\section{Kesimpulan}

Berdasarkan hasil penelitian yang telah dilakukan, maka dapat disimpulkan bahwa Perasan Buah Belimbing wuluh dapat menghambat pertumbuhan Propionibacterium acnes dengan zona hambatan rata-rata yang dihasilkan oleh Perasan Buah Belimbing Wuluh dengan konsentrasi $50 \%$ yaitu $18,67 \mathrm{~mm}$. Konsentrasi $75 \%$ yaitu $18,67 \mathrm{~mm}$. Konsentrasi $100 \%$ yaitu $21 \mathrm{~mm}$. Sedangkan pada kontrol positif yaitu $23,3 \mathrm{~mm}$ dan kontrol negatif yaitu $0 \mathrm{~mm}$.

\section{Saran}

Berdasarkan hasil peneliian yang telah dilakukan makan disarankan untuk melakukan penelitian lebih lanjut tentang identifikasi kendungan kimia yang terdapat dalam Perasan Buah Belimbing Wuluh yang berkhasiat meredahkan peradangan.

\section{DAFTAR PUSTAKA}

Bibiana W.L., (2002), Analisis Mikroba di Laboratorium, PT RajaGrafindo Persada : Jakarta.

Brooks GF, dkk, (2007), Medical Microbiology $23^{\text {th }}$ Edition, United State: The McGraw-hill companies.

Ismayanti, M.D., (2014), Jerawat, (online), Tersedia:

https://mustikadianismayanti08129 6.wordpress.com/2014/11/17/karya -tulis-ilmiah-jerawat/ (12 januari 2017)

Jawetz, E., (2002), Mikrobiologi Kedokteran., Alih bahasa oleh Aryandhito Widhi Nugroho, dkk (Edisi 25), Jakarta : EGC. 
Laianto, S., dkk., (2014), Uji Efektivitas Sediaan Gel Antijerawat Ekstrak Etanol Buah Pare (Momordica charantia) Terhadap Staphylococcus epidermidis dan propionibacterium acnes Dengan Metode Difusi

Mayuna, N.E., (2013), Pengaruh Pemanfaatan Madu Dan Air Perasan Jeruk Nipis Terhadap Penyembuhan Jerawat, Jurusan Kesejahteraan Keluarga Fakultas Teknik Universitas Negeri Padang.

Peraturan Menteri Kesehatan NO. 2406/MENKES/PER/XII/2011,

(2011), Pedoman Umum Penggunaan Antibiotik, Jakarta.

Rahayu, P., (2013), Konsentrasi Hambat Minimum (KHM) Buah Belimbing Wuluh (Averrhoa Bilimbi L) Terhadap Pertumbuhan Candida albicans, Fakultas Kedokteran Gigi Universitas Hasanuddin, Makassar.

Rahmani, S., (2015), Laporan Tetap praktikum Dasar-Dasar Mikrobiologi Akuatik: Isolasi Bakteri, (online), Tersedia: http://aliranirinaunsriakuakultur14. blogspot.co.id/2015/03/isolasibakteri.html (12 Januari 2017).

Sari, A.R., (2015), Pengaruh Ekstrak Daun Ketapang (Terminalia catappa L) Terhadap Pertumbuhan Bakteri Propionibacterium acnes Dan Pemanfaatannya Sebagai Buku Nonteks, Fakultas Keguruan Dan Ilmu Pendidikan Universitas Jember.

Surialaga, S. dkk, (2013), Efek Antihiperkolesterol Jus Buah Belimbing Wuluh (Averhoa bilimbi L.) terhadap Mencit Galur Swiss Webster Hiperkolesterolemia, Departemen Biokimia Fakultas Kedokteran Universitas Padjadjaran Bandung Sekolah Farmasi Institut Teknologi Bandung.

Utami, P.R., (2015), Uji Daya Hambat Perasan Buah Jeruk (Citrus aurantifolia) Terhadap Pertumbuhan Propionibacterium acnes, Politeknik Kesehatan
Kementrian Kesehatan Jurusan Farmasi. Makassar.

Yuliandari, R., (2015), Uji Aktivitas Antibiofilm Sari Buah Belimbing Wuluh (Averrhoa Bilimbi L) Terhadap Biofilm Pseudomonas Aeruginosa Secara In Vitro, UIN Syarifuddin Hidayatullah, Jakarta 